\title{
Intermediate CALGB Criteria
}

National Cancer Institute

\section{Source}

National Cancer Institute. Intermediate CALGB Criteria. NCI Thesaurus. Code C160758.

A rating for AML by CALGB which indicates the outlook on the patient recovery can be considered between favorable and poor. 